\title{
La recuperación de la tradición en los mosaicos del Centro Aletti: La presencia de los Padres de la Iglesia en las reinterpretaciones de las figuras de Noé y Lázaro
}

The Recuperation of the Tradition in the Centro Aletti's Mosaics: The Influence of Patristics in the Reinterpretations of the Figures of Noah and Lazarus

\author{
María RUIZ DE LOIZAGA MARTíN \\ Facultad de Humanidades y Ciencias de la Comunicación \\ Universidad San Pablo-CEU \\ https://orcid.org/0000-0002-9264-5011 \\ maria.ruizloizagamartin@ceu.es
}

\begin{abstract}
In the Centro Aletti's mosaic programs, writings of the Church Fathers and other documents of the East and West Christian tradition form a unit, together with some theological researches of the 19th and 2oth century. The close relationship between word and image is recovered from other artistic periods, such as Early Christian Art. The objective of this article is to analyze in depth the influence of Patristics and Early Christian iconography on the configuration of the Centro Aletti's mosaics, particularly in the reinterpretation of the figures of Noah and Lazarus. These representations underline the story of salvation, reflected in Rupnik's works as the director of the Centro Aletti.
\end{abstract}

Keywords: Marko Ivan Rupnik; Centro Aletti; Liturgical Art.
Resumen: En los programas musivos del Centro Aletti, los escritos de los Padres de la Iglesia y otros textos de la tradición cristiana oriental y occidental forman una unidad con ciertas investigaciones teológicas realizadas en los siglos XX y XXI. La íntima relación entre la palabra y la imagen es recuperada de otros periodos artísticos, como el paleocristiano. El objetivo de este artículo es profundizar en la presencia de la patrística y de la iconografía paleocristiana en la configuración de los mosaicos del Centro Aletti, especialmente, en su reinterpretación de las figuras de Noé y de Lázaro. Estas representaciones subrayan la historia de la salvación, también reflejada en las obras que Rupnik realiza como director del Centro Aletti.

Palabras clave: Marko Ivan Rupnik; Centro Aletti; Arte litúrgico.

\section{INTRODUCCIÓN}

Marko Ivan Rupnik (1954, Zadlog, Eslovenia) es un artista, profesor de la Pontificia Università Gregoriana (Roma), sacerdote jesuita y director del Centro Aletti. Premiado por diversas instituciones, ha desempeñado distintos cargos. Desde el año 2006 es miembro de la Academia Europea de las Artes y las Ciencias, como 
reconocimiento a la labor que realiza como director del Centro Aletti. Asimismo, desde 2012 es consultor del Pontificio Consejo para la Promoción de la Nueva Evangelización y desde 2017, consultor de la Congregación para el Culto Divino y la Disciplina de los Sacramentos.

El principal objetivo del Centro Aletti es estudiar el impacto del cristianismo y de las dinámicas culturales de nuestro tiempo, teniendo en cuenta la tradición cristiana oriental y occidental. Inaugurado por san Juan Pablo II en 1993, dos años más tarde nace su taller de arte espiritual, con sede en Roma, y desde ese momento no ha cesado de realizar obras en América, Oriente Medio, Australia y más de quince países de Europa. Ha recibido constantes bendiciones de san Juan Pablo II, Benedicto XVI y del papa Francisco. Investigadores de reconocido prestigio en el ámbito del arte sacro han subrayado la importancia de sus obras, como monseñor Timothy Verdon, que defiende que la capilla Redemptoris Mater (1996-1999) es la realización artística más importante del pontificado de Juan Pablo $\mathrm{II}^{1}$. Aunque en el Centro Aletti se estudian y crean diversas técnicas -mosaico, vidriera, pintura o escultura-, el mosaico es el protagonista.

Una de las principales preocupaciones del Centro Aletti es realizar un arte de carácter litúrgico, aquel que, en palabras de Rupnik, es parte constitutiva de la liturgia, de forma que sigue revelando el mismo Misterio de la propia liturgia incluso cuando esta no se celebra ${ }^{2}$.

En relación con el arte litúrgico, debemos tener en cuenta que ya en el año 787, en el segundo Concilio de Nicea, VII concilio ecuménico de la Iglesia católica, se establece que la imagen en que se hace visible el misterio del Dios invisible es parte integrante del culto cristiano ${ }^{3}$. De este modo, el arte litúrgico no es simplemente una decoración del espacio, sino que asume una misión propia dentro de la liturgia: crear un espacio donde el misterio de la fe se haga presente. Esta definición de arte litúrgico está muy ligada a lo que Romano Guardini llama imagen de culto, cuyo sentido es que Dios se haga presente ${ }^{4}$. Rupnik además plantea que el arte litúrgico tiene dos dimensiones: una dimensión de la percepción personal, ligada a la acogida de la fe y constituida por las coordenadas culturales en las que

1 Timothy Verdon, Giovanni Paolo II e le arte visive, en Arte Cristiana, 828 (2005), p. 165.

2 Marko Ivan RUPNIK, Una belleza para el encuentro, Madrid, 2013, p. 26. Véase también: Marko Ivan RUPNIK, Applicazione del Concilio: quale arte per la liturgia?, en Notitiae, 471-472 (2005), p. 179.

3 Joseph RATZINGER, El espiritu de la liturgia, Una introducción, Madrid, 2007, p. 162.

4 Romano GUARDINI, Imagen de culto e imagen de devoción. La esencia de la obra de arte, Madrid, 1960, pp. 17-26. 
se configura la obra, y otra de la objetividad de la revelación de Cristo, que rechaza la posibilidad de mostrar la idea individual de Dios ${ }^{5}$.

Así, en la configuración de las obras realizadas por el Centro Aletti influyen ciertos elementos, como la memoria de la Iglesia, la recuperación de la tradición, ya que Rupnik defiende que un verdadero arte litúrgico es aquel que aprende de las grandes épocas de este arte que han elaborado una especie de constitución de su lenguaje ${ }^{6}$. Concretamente, confiesa: «rezo, escucho, estudio un poco de románico, gótico, bizantino. Leo a los Padres de la Iglesia, las Sagradas Escrituras, y entonces nacen las imágenes» ${ }^{7}$.

Del mismo modo, a la hora de estudiar los mosaicos del Centro Aletti, se debe tener presente la relación entre sus fórmulas de representación y determinadas fuentes literarias vinculadas a la teología. En este sentido, no solo se advierte la influencia de escritos de Padres de la Iglesia y de los textos de la tradición cristiana, sino también de ciertas investigaciones realizadas en los siglos XX y XXI. Soloviev (1853-1900), Ivanov (1866-1949), Frank (1877-1950) o Florenski (1882-1937) son algunos autores que nos permiten interpretar el carácter conceptual de las propuestas formales de dichos mosaicos. En definitiva, en las obras del Centro Aletti, la patrística, la tradición oriental y la occidental, así como la teología actual forman una unidad.

Esta armonización de la tradición y la contemporaneidad se aprecia asimismo en el estudio artístico y formal de estas obras. Además de inspirarse en el arte paleocristiano, bizantino, románico o gótico, Rupnik quiere acercar el mensaje de los programas musivarios con un lenguaje actual, por lo que recibe influencia de algunos movimientos y artistas de vanguardia. De este modo, la repercusión de Henri Matisse (1869-1954) puede percibirse en el uso de los colores y de las líneas. En este sentido, destaca el papel de la línea en la búsqueda de la esencialidad de la obra de arte y en su utilización como generadora de movimiento. Su fuerza se percibe de modo patente en los pronunciados contornos curvos de las figuras.

5 Pablo Velasco Quintana y María Rodríguez Velasco, Marko Ivan Rupnik. Una nueva forma de creación frente al subjetivismo contemporáneo, en Debate Actual, 13 (2009), p. 127.

6 Según Rupnik, otros elementos del arte litúrgico son: la eclesialidad, el lenguaje de la propia liturgia, la inspiración del Espíritu Santo, la simplicidad, la significación de la luz y el protagonismo de la materia (Marko Ivan RUPNIK, Applicazione del Concilio... [ver n. 2], p. 583. María RUIZ DE LOIZAGa MARTÍN, Hacia un arte litúrgico, según la concepción de Marko Ivan Rupnik. Reflexiones sobre el arte sacro, en Scripta Theologica. 49 (2017), pp. 619-643.

7 Pablo Velasco Quintana y María Rodríguez Velasco, Marko Ivan Rupnik... [ver n. 5], p. 124. Véase también: Nataša GOVEKAR, El rojo de la Plaza de Oro. Entrevista de Nataša Govekar con Marko Ivan Rupnik sobre arte, fe y evangelización, Burgos, 2013, p. 102. 
De hecho, en los mosaicos del Centro Aletti, algunos perfiles parecer ser extraídos directamente de los dibujos de Matisse ${ }^{8}$. Asimismo, en estas obras musivas se subrayan las propiedades matéricas. Las teselas están compuestas por elementos pétreos, textiles, conchas o cuerdas. Rupnik destaca la influencia del arte contemporáneo -y, en particular, del informalismo- en la valoración de la materia. Características de obras de Georges Mathieu (1921-2012), Antoni Tàpies (19232012), Robert Rauschenberg (1925-2008) o Jasper Johns (1930) se reflejan en sus mosaicos y le han ayudado a investigar en su lenguaje formal. Además, la técnica musivaria puede vincularse a ciertas tendencias del arte contemporáneo y, al mismo tiempo, mira al pasado.

No obstante, a pesar de la importancia de estos elementos, en este artículo se analiza principalmente la influencia de los Padres de la Iglesia y del arte paleocristiano en la configuración de los programas musivos del Centro Aletti, en especial, en su reinterpretación de las figuras de Noé y de Lázaro. La repercusión del arte paleocristiano en las obras de Rupnik puede percibirse en su representación de las imágenes-signo paleocristianas -como el pez, el pan, el pelícano o la serpiente ${ }^{9}$-, de las prefiguraciones -como de Adán, Noé, Isaac, José o los tres jóvenes babilonios- y de los episodios neotestamentarios, fundamentalmente de algunos milagros, como el relativo a la resurrección de Lázaro.

La elección, como objeto de estudio de la presente investigación, de Noé y de Lázaro, figuras más bien excepcionales dentro de la producción artística del Centro Aletti, se debe a que en su configuración es especialmente palpable la influencia de la patrística y del arte paleocristiano. Además, estos dos personajes, presentes en obras iniciales del Centro Aletti, como en la capilla Redemptoris Mater (1996-1999) o en el comedor del Centro Aletti en Roma (2002), han seguido formando parte de programas musivos posteriores, por lo que es posible trazar una evolución en sus representaciones, que refuerza la concepción del Centro Aletti como un taller vivo, que ha experimentado diversos cambios desde que realizara sus primeros mosaicos hasta la actualidad. Dado que en las obras de Rupnik forma y contenido han de estudiarse conjuntamente, el análisis de estos cambios formales estará acompañado de una explicación acerca del sentido de dicha transformación. En este estudio juegan un importante papel las fuentes patrísticas al

8 María RUIZ DE LOIZAGa MARTíN, La semplificazione delle forme. Influenza di Matisse nei mosaici di Marko Ivan Rupnik e il Centro Ezio Aletti, en Collectanea Franciscana, 87 (2017), pp. 613-634.

9 Para profundizar en esta reinterpretación de las imágenes-signos desarrolladas por el Centro Aletti, véase: María RODRÍGUEZ VELASCO (ed.), Tradición y Modernidad en la obra de Marko Iván Rupnik, Madrid, 2013, pp. 82-89. 
ser las que, mediante un análisis iconológico, nos permiten interpretar el sentido global de las representaciones de estas dos figuras. Además, nos serviremos del método comparativo para enfatizar la correlación entre dichas representaciones y las presentes en el arte paleocristiano.

\section{LA INSPIRACIÓN EN MODELOS ICONOGRÁFICOS PALEOCRISTIANOS}

Una de las fuentes principales de los mosaicos del Centro Aletti es el arte paleocristiano, un arte que se desarrolló a partir del siglo II, tal y como informan los testimonios literarios ${ }^{10}$. Entre las representaciones paleocristianas más antiguas que podemos contemplar en la actualidad hay que destacar, por un lado, la importancia de los ciclos de imágenes que se encontraron en una pequeña iglesia en Dura Europos (Siria). Por otro lado, destacan las representaciones de las catacumbas italianas, especialmente, las romanas. Con relación a las catacumbas, Rupnik ha remarcado que el hecho de que se localicen en el ámbito funerario refleja precisamente la auténtica novedad del cristianismo: la vida eterna en Cristo $^{11}$. Es también en Roma donde se sitúan algunos de los programas musivos paleocristianos más importantes, como los que pueden contemplarse en la basílica de Santa María la Mayor. El Centro Aletti, con su sede en Roma, más concretamente en Via Paolina, a unos pasos de esta basílica, toma referencia directa de esta construcción y de sus mosaicos.

El hieratismo, la esencialidad, la rica policromía, el carácter simbólico y comunicativo, el realismo o la unidad entre el texto y la imagen son algunas de las principales características del arte paleocristiano que son recuperadas por Rupnik. Tras su aparente sencillez, las imágenes paleocristianas transmiten un mensaje profundo, ligado, en muchas ocasiones, a la formación de los primeros

10 Martine DulaEY, Bosques de símbolos. La iniciación cristiana y la Biblia (siglos I-IV), Madrid, 2003, p. 47. Hay que precisar que no existe unanimidad entre los investigadores sobre el nacimiento del arte paleocristiano. Si Dulaey habla del siglo II, otros autores señalan el siglo III (Véase: André GRABAR, Las vías de la creación en la iconografía cristiana, Madrid, 1993, p. 17; María Antonietta CRIPPA, Julien RIES y Mahmoud ZIBAWI (ed.), El arte paleocristiano. Visión y espacio de los orígenes a Bizancio, Madrid, 1998, p. 70). Por ello, García Mahíques y Bernardi concluyen que la imagen cristiana hace su aparición entre las últimas décadas del siglo II y comienzos del III (Rafael GARCÍA MAHÍQUES, La adoración de los Magos. Imagen de la epifanía en el arte de la antigüedad, Vitoria, 1992, p. 22; Piergiuseppe BERNARDI, I colori di Dio. L'immagine cristiana fra Oriente e Occidente, Genova, 2007, p. 27).

11 Nataša GovEKar, El rojo de la Plaza de Oro... [ver n. 7], p. 75. 
cristianos. Podrían constituir una catequesis, para instruir a los fieles. También pueden ser comprendidas como el reflejo de la enseñanza recibida. No obstante, dada su íntima relación con el Más Allá y con el poder salvífico de Dios, autores como Plazaola han señalado que, más que una catequesis o exposición doctrinal, estas imágenes deberían concebirse como una «plegaria figurada», vinculadas a las commendatio animae ${ }^{12}$. Por tanto, la elección de los diversos episodios de la salvación no era aleatoria, sino que su representación se relacionaba directamente con estas oraciones y plegarias de carácter litúrgico-funerario.

Además, debemos recordar que no solo querían ofrecer un recuerdo del pasado, sino una verdad perenne, de tal manera que su contemplación hace que seamos hoy testigos de un evento que también nos implica a nosotros. Por tanto, el arte paleocristiano, que emerge como el testimonio más antiguo de las representaciones artísticas cristianas, está íntimamente ligado a la liturgia y quiere hacer presente el valor salvífico de los sacramentos ${ }^{13}$. Esta concepción de las imágenes será recuperada por el Centro Aletti, pues sus mosaicos no se proponen como simple recuerdo de escenas históricas del pasado, ni como copias de la antigüedad, sino como imágenes vivas ${ }^{14}$. En este sentido, debemos subrayar la reinterpretación que hace Rupnik de estas imágenes, ya que si en el arte paleocristiano estaban ligadas al contexto funerario, en el Centro Aletti las encontramos en diversos espacios, como en iglesias o comedores. Es decir, se adaptan modelos y se reinterpretan en ámbitos no necesariamente funerarios, lo que origina nuevas interpretaciones de dichas imágenes.

Por otro lado, conviene también señalar que los artífices de estas representaciones paleocristianas en ocasiones se sirvieron de recursos precristianos y se inspiraron en el estilo romano de la época para realizar sus imágenes, a las que invistieron de un nuevo sentido, lo que se conoce como migraciones tipológicas ${ }^{15}$. Grabar así afirma que el arte paleocristiano no reemplazó al arte antiguo, sino que fue una rama de él ${ }^{16}$. Beckwith señala que muchas de las formas propias del arte paleocristiano fueron extraídas inicialmente de las tradiciones del paganismo y de las judías helenísticas y, de forma paulatina, fueron configurando un ciclo

12 Juan PlazaOla, Historia del arte cristiano, Madrid, 1999, p. 11. Véase también: Santiago SEBASTIÁN, Mensaje simbólico del arte medieval. Arquitectura, Liturgia e Iconografía, Madrid, 2009, p. 145.

13 Vincenzo GATTI, L'arte nella chiesa, en Arte Cristiana 748 (1992), p. 51.

14 Además, su iconografía siempre se adaptará a la finalidad del espacio que decora y al carisma que lo inspira (María RODRÍGUEZ VELASCO, Tradición y Modernidad... [ver n. 9], p. 91).

15 Rafael GARCÍA MAHÍQUES, Iconografía e iconología. 1. La historia del arte como historia cultural, Madrid, 2008, p. 25.

16 André GRABAR, El primer arte cristiano (200-395), Madrid, 1967, p. 2. 
ilustrativo cristiano de notable complejidad ${ }^{17}$. Por su parte, Zibawi completa estas reflexiones al explicar que, sin romper con la tradición heredada, se adoptaron y ordenaron los elementos «siguiendo una nueva visión creativa» ${ }^{18}$. La propia técnica musiva desarrollada durante el arte paleocristiano, y en la actualidad recuperada por diversos artistas como Rupnik, puede considerarse una reminiscencia de la tradición musivaria del arte clásico.

Rupnik explica que cada representación en el arte paleocristiano «se convierte en un elemento de encuentro entre cristianos, una especie de "símbolo" en el que se reconocen ${ }^{19}$. Una de las características esenciales del símbolo, según el director del Centro Aletti, es que revela un conocimiento integral ${ }^{20}$. Pues bien, el arte del primer milenio presenta una visión integradora, ya que, como señala Rupnik, es un arte «que nunca ha separado las cosas $»^{21}$.

Además de la mentalidad simbólica, la comunión emerge como una característica propia del arte paleocristiano. Como ha señalado el director del Centro Aletti, el elemento esencial en los inicios del arte cristiano es la comunicación: «Con la primera pintura cristiana aparece una dimensión "nueva": la comunicación de Cristo y de lo que Él ha realizado»²2. Por ello, en otra ocasión, Rupnik matiza y señala que la pregunta que hemos de hacernos no debe ser ¿qué se comunica?, sino ¿quién se comunica?, ya que «mediante este arte pasa la memoria de una Persona viva», pues intenta hacer ver las cosas, la creación y la humanidad, tal como son en Cristo y según Cristo. Y, precisamente, esta concepción del arte como espacio de encuentro es percibida por Rupnik como la novedad absoluta que el cristianismo introduce en el arte ${ }^{23}$.

Asimismo, a esta comunicación de las representaciones paleocristianas se llega a partir de dos cualidades propias de este arte: el realismo y el contenido ideal, tal y como explica Rupnik ${ }^{24}$. Realismo porque es necesario que resulte inteligible, que pueda descifrarse sin equívocos -a pesar de que las imágenes cristianas

17 John BECKWITH, Arte paleocristiano y bizantino, Madrid, 1997, p. 62.

18 María Antonietta CRIPPA, Julien RIES y Mahmoud ZIBAWI (ed.), El arte paleocristiano... [ver n. 10], p. 307.

19 Tomáš ŠPIDLÍK y Marko Ivan RUPNIK, La fe según los iconos, Burgos, 2003, pp. 10-11; y Tomáš ŠPIDLÍK y Marko Ivan RUPNIK, Narrativa dell'immagine, Roma, 1996, p. 9.

20 Mariano APA, Olivier ClÉMEnT y Crispino VALENZIANO (ed.), La Capilla Redemptoris Mater del Papa fuan Pablo II, Burgos, 2002, p. 183.

21 Nataša GoveKar, El rojo de la Plaza de Oro... [ver n. 7], p. 185.

22 Tomáš ŠPIDLÍK y Marko Ivan RUPNIK, La fe... [ver n. 19], p. 11.

23 Nataša GOVEKaR, El rojo de la Plaza de Oro... [ver n. 7], pp. 75-76.

24 Ibid. [ver n. 7], p. 76. 
iniciales sean concebidas con una gran economía de medios, presenten un cierto hieratismo, lenguaje sintético, y estén limitadas a lo estrictamente esencial- ${ }^{25}$. Esta simplificación, por tanto, no descarta el naturalismo ${ }^{26}$. En concreto, Rupnik señala que «lo real se respeta en su esencialidad, pero no se hace de ello una elaboración detallada, ya que el detalle molestaría ${ }^{27}$. Es una pintura que sugiere, un arte que no presta atención a lo accesorio. En este sentido, debemos recordar que, según el director del Centro Aletti, la simplicidad es una de las características del arte litúrgico.

En relación con el contenido ideal, el director del Centro Aletti subraya que cada representación «no se trata de una idea abstracta, sino de la idea en el sentido del Logos y por tanto de un misterio de Cristo que se nos participa ${ }^{28}$. Precisamente, este contenido ideal se refleja en una de las propiedades esenciales del arte de los primeros cristianos: la unidad entre el texto y la imagen. El estudio del arte paleocristiano evidencia que la Sagrada Escritura fue para los primeros cristianos la fuente más directa y eficaz de inspiración, y que los autores de diversos escritos también ahondaron en el significado concreto de cada una de las representaciones. Debemos ser conscientes de la advertencia que plantea en este sentido Dulaey: cuando estudiamos el arte paleocristiano no se puede pretender una relación directa entre una pintura de un momento determinado y unos escritos datados en las mismas fechas, pues «los azares de la historia hacen que, en un lugar y en un tiempo dados, tengamos a veces una amplia cosecha de imágenes y no de textos, o a la inversa $\gg^{29}$. No obstante, ello no significa que se deba rechazar dicho acercamiento. Así, Grabar también señala que, aunque sean escasos los textos que tengan la misma datación que las primeras representaciones pictóricas es importante tener en cuenta esta interrelación entre las fuentes escritas y las artísticas, dado que la elección de los asuntos revela «un conocimiento bastante profundo de la doctrina $\gg^{30}$.

25 Grabar matiza que las primeras imágenes cristianas solo cumplen su función «en la medida en que son claras»y esa claridad puede estar condicionada por la preparación de quien las mira (André GRABAR, Las vías... [ver n. 10], pp. 18-19). El hombre, por tanto, estaba habituado a estos signos que, hoy día, en ocasiones se perciben como jeroglíficos. Véase: Fabrizio BISCONTI, Temi di iconografia paleocristiana, Città del Vaticano, 2000, p. 13; y Timothy VERDON (ed.): L'arte cristiana in Italia. Origini e Medioevo, Milano, 2005, p. 51.

26 María Antonietta CRIPPA, Julien RIES y Mahmoud ZIBAWI (ed.), El arte paleocristiano... [ver n. 10], p. 79.

27 Nataša GOVEKAR, El rojo de la Plaza de Oro... [ver n. 7], p. 76.

28 Ibid. [ver n. 7], p. 76.

29 Martine DulaEY, Bosques de símbolos... [ver n. 10], pp. 53-54.

30 André GRABAR, El primer... [ver n. 16], p. 27. 
Por todo ello, en la explicación de las figuras de Noé y de Lázaro, tal y como hacen investigadores como Dulaey en sus estudios, relacionaremos dichas imágenes con unos textos que no tienen por qué ser estrictamente contemporáneos ni geográficamente próximos, pero que, sin embargo, sí explican el sentido y el alcance de las representaciones paleocristianas. De este modo, a través de las escenas pictóricas de las catacumbas o de Dura Europos, escultóricas de los sarcófagos o musivarias, nos serviremos de los textos de las Escrituras, liturgia, sermones o tratados teológicos para su comprensión. Es decir, trataremos de hacer patente lo que afirmó san Basilio (ca. 330-379) al escribir que aquello que se explica con palabras, la pintura muda lo muestra por la imitación ${ }^{31}$.

Además, la recuperación de los textos de los Padres de la Iglesia y de otros autores pertenecientes al cristianismo primitivo es una de las claves seguidas por Rupnik para la configuración de sus diversas escenas ${ }^{32}$. Como subraya Rodríguez Velasco, «al abordar la selección de los temas representados en los mosaicos se hace más evidente la recuperación de la tradición en las fuentes literarias que inspiran las obras, fundiéndose la patrística con la teología actual, la tradición occidental y la oriental» ${ }^{33}$. Por todo ello, estos textos nos servirán no solo para ilustrar y completar el significado de las imágenes paleocristianas, sino también para comprender el sentido último de las representaciones musivas desarrolladas por el Centro Aletti en la actualidad.

\section{LAS PREFIGURACIONES: EL CUMPLIMIENTO DEL ANTiguo Testamento EN EL Nuevo}

Es principalmente a comienzos del siglo IV, al promulgarse en el año 313 el Edicto de Milán por parte del emperador Constantino, cuando el carácter narrativo-descriptivo de las representaciones se impondrá con mayor fuerza que el simbólico. Como señala Grabar, primeramente, encontramos imágenes esquemáticas, «de la máxima concisión; se tiende después a completarlas, a hacerlas

31 Basilio de Cesarea, Operum D. Basilii Magni caesariae Cappadociae quondam archiepiscopi prior tomus, Parisiis, 1547, f. 128r.

32 Además, el propio Centro Aletti explica así algunos de sus mosaicos. Véase: Nataša GovEKAR, La vita in Cristo con i mosaici della cripta di San Pio, Roma, 2014, p. 3.

33 María RodrígueZ Velasco, Iconografía, imagen y estética en los mosaicos de Marko Ivan Rupnik: una mirada desde la tradición, en Debate Actual 13 (2009), p. 19. 
más exactas, de tal forma que a finales del siglo IV ya tenemos figuraciones de escenas o de personajes con carácter bien individualizado» ${ }^{34}$. Špidlík y Rupnik también han comentado esa transformación al escribir que incluso se puede decir que el elemento ilustrativo está prácticamente ausente en el arte paleocristiano de los primeros siglos y que la verdadera representación figurativa solo la encontraremos siglos más tarde ${ }^{35}$. La selección y unidad de los programas decorativos desarrollados serán determinados por diversos criterios, entre los cuales, destaca el de la prefiguración. La fuente de esta conformidad entre el Antiguo y el Nuevo Testamento reside, en primer lugar, en el propio Cristo, que remarcó en varias ocasiones esta unidad entre los dos tiempos (Mt 5,17; Lc 18,31; Lc 24,44). San Pablo, con posterioridad, también subrayará esta correlación (Rom 5,14; Col 2,17), que será asimismo profundizada por diversos autores. San Ireneo (ca. 130ca. 202) así escribe:

Nuestro Señor Jesucristo, que en la plenitud de los tiempos se ha hecho hombre entre los hombres para poder enlazar el fin con el principio, esto es, el hombre con Dios. He aquí por qué los profetas, después de haber recibido el carisma profético del mismo Verbo, predicaron su venida según la carne, por la cual la mezcla y comunión de Dios y del hombre se realizó según el deseo del Padre (Libro IV, 20.4) ${ }^{36}$.

San Justino (ca. 100/114-162/168) subraya la simbología de los hechos del Antiguo Testamento (Diálogo con Trifón, 112) ${ }^{37}$, y Orígenes (185-254), que generaliza el uso de las prefiguraciones en el mundo oriental para el estudio de la Biblia, plantea concretamente en Sobre los principios:

Demostrando, de modo sumario, la divinidad de Jesús y exhibiendo las palabras proféticas acerca de él, demostramos juntamente que son divinamente inspiradas las Escrituras que lo profetizan, los textos que anuncian su venida y la enseñanza pronunciada con todo portento y autoridad, y que por esto ha conquistado a los elegidos de entre las naciones. Sin embargo, se debe decir que el carácter divino de las palabras proféticas y el carácter espiritual de la ley de Moisés brillaron [solo] cuando vino Jesús (IV 1,6) ${ }^{38}$.

34 André GRABAR, Las vías... [ver n. 10], p. 95.

35 Tomáš ŠPIDLÍK y Marko Ivan RUPNIK, La fe... [ver n. 19], p. 11.

36 Ireneo, Contra las herejías. Libro IV, ed. por Jesús GARITAONANDIA, Sevilla, 1994, p. 80.

37 Justino, Lo mejor de fustino mártir, Apología I, Apología II. Diálogo con Trifón, ed. por Alfonso ROPERO, Barcelona, 2004, p. 364.

38 Orígenes, Sobre los principios, ed. por Samuel FERNÁNDEZ (Fuentes patrísticas, 27), Madrid, 2015, pp. 813-815. 
Asimismo, san Metodio de Olimpia, a finales del siglo III, y san Hilario de Poitiers (ca. 315-367) se refieren en sus escritos a las profecías como prefiguraciones realizadas a lo largo del tiempo para el conocimiento de la encarnación ${ }^{39}$. San Basilio de Cesarea (ca. 330-379) profundiza sobre la tipología al escribir que «efectivamente, el tipo hace ver, por imitación, aquello que se espera, y de antemano hace entrever ostensiblemente el porvenir» y, a continuación, cita diversos ejemplos de correlación entre los episodios del Antiguo y del Nuevo Testamento ${ }^{40}$. San Juan Crisóstomo (347-407) señala el parentesco entre ambos Testamentos y la armonía de sus escritos (Sermon I) ${ }^{41}$. Y san Agustín (354-430) en Contra Fausto, al plantear que en los textos proféticos se insinúan alegorías, también destaca su simbolismo, que se extenderá en la escuela occidental $(12,7)^{42}$. Asimismo, el obispo de Hipona se preguntará en La Ciudad de Dios: «¿Qué quiere decir, en efecto, Testamento Antiguo sino encubrimiento del Nuevo?; ¿y qué otra cosa el Nuevo, sino revelación del Antiguo?» (XVI, 26,2) ${ }^{43}$.

En definitiva, el Antiguo Testamento no solo ha precedido al Nuevo, sino que lo ha anunciado o prefigurado. Por ello, ambos transmiten el mismo mensaje; no obstante, lo que aparece velado, en forma críptica, en la Antigua Ley, se desvela y revela en los evangelios con un lenguaje inteligible. Esto es fundamental para la revelación bíblica al subrayar la continuidad de la fe ${ }^{44}$. De tal forma que la relación entre los dos eventos, tan lejanos en el tiempo, se trata de un vínculo propiamente ontológico ${ }^{45}$.

Por todo ello, una de las características más significativas del arte paleocristiano a partir del siglo IV será la plasmación de esta correlación entre diversas escenas pertenecientes al Antiguo y al Nuevo Testamento, con el objetivo de

39 Méthode, Du livre Arbitre, ed. por A. VaIllant (Patrologia Orientalis, 22), Turnhour, 2004, p. 729; e Hilario, Tratado de los misterios, ed. por Juan José AYán Calvo (Biblioteca patrística, 20), Madrid, 1993, pp. 35-38.

40 Basilio de Cesarea, El Espíritu Santo, ed. por Argimiro Velasco Delgado (Biblioteca de patrística, 32), Madrid, 1996, p. 156.

41 Jean Chrysostome, Sermons sur la Genèse, ed. por Laurence BROTTIER, Paris, 1998, pp. 155 157.

42 Agustín, Obras completas de san Agustín, XXXI, Escritos antimaniqueos (2 $2^{\circ}$ Contra Fausto), ed. por Pío de Luis, Madrid, 1993, p. 174.

43 Agustín, Obras completas de san Agustín. XVII. La Ciudad de Dios, ed. por Santos SANTAMARTA DEL Río y Miguel FuerTes LANERO, Madrid, 2001, p. 289.

44 André GRABAR, Las vías... [ver n. 10], p. 132; Louis RÉAU, Iconografía del arte cristiano. Introducción general, Barcelona, 2000, p. 251; y Santiago SEBASTIÁN, Iconografía Medieval, Donostia, 1988, p. 106.

45 Enrico MAZZa, Tipologia come metodo di lettura biblica e di fondamento dell'immagine, en Arte Cristiana, 737-738 (1990), p. 107. 
subrayar la continuidad entre ambos. Los artífices de este arte contemplaron en los tipos y figuras del Antiguo Testamento un anuncio de los acontecimientos y personajes del Nuevo Testamento.

Conviene tener en mente que esta correlación entre ambos Testamentos se aprecia claramente en el arte paleocristiano con la representación de escenas del Antiguo y Nuevo Testamento en un mismo espacio, como sucede con las pinturas de Dura Europos. No se sigue ningún orden cronológico, pues los pasajes de la Biblia no son concebidos como meros sucesos de una historia, «sino los signos de una metahistoria siempre viva» ${ }^{46}$. También este fenómeno lo podemos encontrar en los frescos de diversas catacumbas -como en el hipogeo que se halla debajo de la Vía Latina-, en los relieves de la puerta de madera esculpida de Santa Sabina en Roma (siglo V) o en los mosaicos de Santa María la Mayor en esta misma ciudad, en cuyo arco triunfal encontramos escenas del Nuevo Testamento, mientras que en la nave central se narran hechos del Antiguo Testamento (siglo V).

Este hecho también es recuperado por el Centro Aletti, que, al igual que sucede en el arte paleocristiano se preocupa por la creación de programas unitarios. Una de sus miembros, Maria Campatelli, explica esta correlación existente entre los dos testamentos y señala que todo el Antiguo Testamento es figura del Nuevo y que el antiguo evento conduce a la salvación, como veremos a continuación a partir del estudio de la figura de Noét7.

\section{III.1. Noé: Figura del hombre justo en el Antiguo Testamento}

Una de las prefiguraciones de Cristo que encontramos en el arte paleocristiano y que ha sido recuperada por el Centro Aletti es Noé. San Justino en su Diálogo con Trifón comentó su correspondencia con Jesús, pues Él es «principio de un nuevo linaje, por Él regenerado con el agua de la fe y el madero, que contenía el misterio de la cruz, al modo que también Noé se salvó con los suyos llevado en el madero del arca sobre las aguas $\gg^{48}$. Por su parte, san Melitón de Sardes, que murió hacia el año 180, centrará su paralelismo entre Noé y Cristo, al plantear

46 María Antonietta CRIPPA, Julien RIES y Mahmoud ZIBAWI (ed.), El arte paleocristiano... [ver n. 10], p. 73.

47 Maria Campatelli, Leggere la Bibbia con i Padri. Per una lettura credente delle Scritture, Roma, 2009, p. 159.

48 Justino, Lo mejor de fustino mártir... [ver n. 37], p. 409. 
que ambos son los pilotos, quienes dirigen la barca $(\text { Sur la foi, XV,15 })^{49}$. En el siglo IV, Asterio de Amasea, y, con posterioridad, Juan Damasceno (676-749) escriben que Noé encerrado en el arca es tipo de Cristo en el sepulcro y ambos, de este modo, salvan al género humano ${ }^{50}$. Como dice Orígenes, Noé salvado del diluvio también representa a la humanidad nueva y es asimismo el que la recrea (Homily $4,8,2)^{51}$. San Cirilo de Alejandría (ca. 370/373-444) planteará algo semejante: «Noé verdadero autor del segundo nacimiento» (Catequesis 17,10) (22 $^{52}$.

Por otro lado, si Noé es Cristo, el arca es la Iglesia y la cruz $^{53}$. En la cita de Justino expuesta ya se aprecia esta identificación entre el arca y la cruz, cuando se afirma que Cristo ha regenerado «con el agua de la fe y el madero», del mismo modo que «Noé se salvó con los suyos llevado en el madero del arca sobre las aguas» (Diálogo con Trifón, 138). También Fírmico Materno, ya en el siglo IV, indirectamente señala este paralelismo al escribir que el arca salvó al género humano del diluvio universal (XXVII, 3$)^{54}$.

La escena de Noé, además, se verá como una prefiguración del bautismo ${ }^{55}$. Ciertamente, muchos autores y Padres de la Iglesia no solo establecían relaciones entre figuras del Antiguo y Nuevo Testamento, sino que también reconocían alusiones a los sacramentos en los acontecimientos del Antiguo Testamento. Es decir, la tipología del Antiguo Testamento no solo se cumple en la persona de Cristo, sino también en la propia Iglesia. Así, los episodios en los que se mencione el agua serán los antetipos del sacramento del bautismo, pues, como escribe Daniélou, el agua es principio de destrucción, al ser el instrumento del juicio que aniquila al mundo pecador, pero asimismo es principio de creación, pues emerge como el medio vivificante en que nace la nueva criatura ${ }^{56}$. Ya en la primera carta

49 Melitón, Sur la Pâque et fragments, ed. por Othmar PERLER, Paris, 1966, p. 241.

50 SS. Patrum, Aegyptiorum. Opera omnia. Praecedunt Philonis Carpasii, Asterii Amaseni, Nemesii Emeseni, Hieronymi Graeci, Turnholti, 1967, p. 447; y Juan Damasceno, Homilías cristológicas y marianas, ed. por Guillermo PONS, Madrid, 1996, p. 94. Véase también: ISIDORVs, Expositio in Vetus Testamentum Genesis, Freiburg, 2009, p. 30.

51 Origen, Homilies 1-14 on Ezekiel, ed. por Thomas P. SCHECK, New York, 2010, p. 76.

52 Cirilo de Jerusalén, Catequesis, ed. por Jesús SANCHO BIELSA, Madrid, 2006, p. 397.

53 Martine DulaEY, Bosques de símbolos... [ver n. 10], p. 229; y Jean DaNIÉLOU, Símbolos cristianos primitivos, Bilbao, 1993, p. 60.

54 FIRMICO MATERNO, L'errore delle religioni pagane, ed. por Ennio SANZI, Roma, 2006, p. 165.

55 Comentarios sobre los mosaicos de la Parroquia de María Inmaculada en Modugno, realizados por el Centro Aletti-Véase: https://www.centroaletti.com/opere/chiesa-maria-immacolata-modugno-ba-2007/ [consultado: 08-06-2019]

56 Jean DaniéLOU, Sacramentos y culto según los santos Padres, Madrid, 1964, pp. 15 y 88 . Véase también: Martine DulaEY, Bosques de símbolos... [ver n. 10], p. 229. 
de san Pedro encontramos esta relación (1Pe 3,20-21), que será continuada por otros autores, como Asterio de Amasea ${ }^{57}$. San Ambrosio de Milán (ca. 340-397) se dirige a los neófitos en estos términos:

También en el diluvio hay una figura anticipada del bautismo (...). En aquel diluvio, hizo perecer toda la corrupción de la carne e hizo subsistir únicamente el linaje y el tipo del justo. ¿No es acaso este diluvio, lo que es el bautismo, por el cual se borran todos los pecados, y solo resucitan el alma y la gracia del justo? (Los sacramentos II, 1$)^{58}$.

Por su parte, san Agustín compara el sentido salvífico de la barca de Noé con el propio del sacramento del bautismo, que salva «no quitando la suciedad de la carne, sino demandando una buena conciencia» (Tratado sobre el bautismo. Libro $V, 39)^{59}$.

Tanto en la narración del diluvio de Noé como del bautismo de Cristo, la paloma adquiere un importante papel, lo que permite a algunos autores enlazar ambas escenas. Es el caso de san Máximo de Turín que, en uno de sus sermones en el siglo IV, señala que si la paloma con una rama de olivo anunció a Noé la seguridad, es la paloma del Espíritu Santo la que en el bautismo de Cristo, como muestra de su divinidad, otorga la salvación eterna (Sermon 64) ${ }^{60}$. No obstante, este protagonismo de la paloma ya fue previamente apuntado por Tertuliano (160-ca. 220), que compara la paloma de Noé con la imagen del Espíritu Santo en forma de paloma que está presente en todo nuevo bautismo:

pues lo mismo que, después de las aguas del diluvio, con las que fue limpiada la antigua iniquidad (...) anunció a las tierras como un pregonero el cese de la ira de Dios, así -con el mismo tipo de plan, pero de eficacia espiritual- la paloma del Espíritu Santo, enviada desde los cielos trayendo la paz de Dios, vuela hacia la tierra de nuestra carne al salir del baño, tras [serle perdonados] sus antiguos pecados, en todo lo cual la Iglesia corresponde a la figura del arca ${ }^{61}$.

Por tanto, Tertuliano plantea este paralelismo de la paloma en ambos pasajes, pero también incorpora una nueva correspondencia: el arca de Noé como figura de la Iglesia -se relaciona, por tanto, con la imagen de la Iglesia como nave-.

57 SS. Patrum, Aegyptiorum... [ver n. 50], p. 447.

58 Ambrosio, Explicación del símbolo, Los sacramentos. Los misterios, ed. por Pablo CERVERA BARRANCO, Madrid, 2005, p. 81.

59 Agustín, Obras completas. XXXII. Escritos antidonatistas, Madrid, 1988, p. 165.

60 Maximus, The sermons of St. Maximus of Turin, Newman Press, New York, 1989, p. 158.

61 Tertuliano, El bautismo. La oración, Madrid, 2006, pp. 133-137. 
Esta imagen también es tratada por otros autores, como Gregorio de Elvira, que en la segunda mitad del siglo IV, afirma que la «construcción del arca señalaba claramente la figura de nuestra Iglesia» (Sobre el arca de Noé, 4-5) ${ }^{62}$. San Agustín profundizará, entre otros aspectos, en esta relación al plantear las características del arca de Noé y la nave de la Iglesia: «Tenía la entrada por un costado: pues nadie entra en la Iglesia si no es por el sacramento del perdón de los pecados, sacramento que manó del costado abierto de Cristo» (Contra Fausto 12,14) ${ }^{63}$.

No obstante, hay que señalar que estas significaciones de Noé como prefiguración de Cristo, el arca como la cruz, la escena del diluvio como prefiguración del bautismo y el símbolo del arca de Noé como la Iglesia no deben ser interpretadas de manera autónoma, sino de forma global. De hecho, en algunos escritos así lo encontramos, como en san Justino, tal y como hemos señalado. Es el caso también de san Ambrosio, que escribe:

Ves el agua, ves el leño, captas la paloma ¿y dudas del misterio? El agua es donde la carne se sumerge, para que se borre todo pecado de la carne. Allí es sepultado todo delito. El leño es en el que fue clavado el Señor Jesús cuando padeció por nosotros. Está la paloma, bajo cuya apariencia descendió el Espíritu Santo, como lo aprendiste en el Nuevo Testamento, que te inspira la paz del alma, la tranquilidad de la mente (Los misterios 10-11) ${ }^{64}$.

También en este sentido debemos entender las palabras de san Agustín: «Noé, con los suyos, se libra gracias al agua y a un madero: igual que la familia de Cristo se libra por el bautismo de Cristo sellado con la pasión en la cruz» (Contra Fausto 12,14) ${ }^{65}$.

En definitiva, entre los primeros cristianos las escenas referidas a Noé adquieren un significado salvífico y reflejan la misericordia de Dios. Son una prefiguración de la redención. Noé se salvó junto con su familia en el arca, del mismo modo que Cristo, triunfante de la muerte, salva a la Iglesia ${ }^{66}$.

62 Gregorio de Elvira, Obras completas, Madrid, 1989, p. 227.

63 Agustín, Obras completas de san Agustín, XXXI... [ver n. 42], p. 187. Véase también: Isidorvs, Expositio in Vetus... [ver n. 50], p. 30-31. El Centro Aletti en su explicación de los mosaicos de la parroquia de María Inmaculada en Modugno hace alusión a esta explicación de san Agustín. Véase: https://www.centroaletti.com/opere/chiesa-maria-immacolata-modugno-ba-2007/ [consultado: 08-06-2019]

64 Ambrosio, Explicación del símbolo... [ver n. 58], p. 145.

65 Agustín, Obras completas de san Agustín, XXXI..., [ver n. 42], p. 185. Véase también: Agustín, Obras completas de san Agustín. XVII, [ver n. 43], p. 216.

66 Juan PlazaOla, Historia del arte... [ver n. 12], p. 12. 
Precisamente, este es el sentido con el que deben ser concebidas las diversas representaciones que encontramos de Noé en el arte paleocristiano. Es importante tener en mente que existen de este patriarca un gran número de imágenes, aunque estas no aparecen hasta finales del siglo $\mathrm{III}^{67}$. En ellas Noé suele representarse solo, saliendo del arca o después del diluvio mostrando los brazos elevados al cielo o tendidos para acoger la paloma que porta el ramo de olivo, como contemplamos en la catacumba de los Santos Marcelino y Pedro de Roma.

En las representaciones de Noé realizadas por el Centro Aletti también se persigue reflejar la misma simbología que en las escenas paleocristianas. Por ello, aparece el patriarca en posición orante o recibiendo la rama de olivo que porta la paloma, como observamos en la capilla Redemptoris Mater de la Ciudad del Vaticano (1996-1999) (Fig. 1). Quizás la mayor diferencia que encontramos entre estas representaciones musivas y las primeras obras cristianas reside en el hecho de que en las obras realizadas por el Centro Aletti, la escena se enriquece con un mayor número de elementos. Así, además de la figura de Noé, del arca y de la paloma con la rama de olivo, también podemos observar diferentes animales como símbolo de todas las parejas que tomó el patriarca, tal y como nos cuenta el pasaje bíblico (Gn 7,1-9). Concretamente, la selección de los mismos en la parroquia de María Inmaculada en Modugno, en Italia (2007) no es casual, pues se vinculan a otros pasajes bíblicos (Fig. 2). Así, el lobo y el cordero aparecen en la profecía de Isaías (Is 65,25); la mula y el buey, en los evangelios apócrifos como testigos del nacimiento de Cristo; y el mismo buey, junto con el león y el águila son los símbolos de tres de los evangelistas. Junto a ellos, aparecen también lirios que fueron mencionados por el propio Cristo (Mt, 6,25-28; Lc 12,27) ${ }^{68}$. Por otro lado, Dios dio a Noé instrucciones muy concretas para la construcción del arca, que presentaba tres pisos $(\mathrm{Gn} 6,16)$, tal y como observamos en esta representación de Modugno o en la que se localiza en la iglesia ortodoxa de Cluj (Rumanía). En ambas, además, se observa el signo de la cruz en medio de la barca. De este modo, el Centro Aletti también recoge la vinculación entre el arca y la cruz, que escribieron tantos autores primitivos.

67 Martine Dulaey, Bosques de símbolos... [ver n. 10], p. 251. Como ha notado Gombrich, los artífices no se preocupan por la relación del tamaño del arca y de Noé -de hecho, el arca es mucho más pequeña que el patriarca-, sino que, al igual que sucede en otras representaciones de los primeros cristianos, lo realmente importante es la simbología de la imagen (Ernst H. GOMBRICH, Los usos de las imágenes. Estudios sobre la función social del arte y la comunicación visual, Barcelona, 2003, p. 25).

68 Comentarios sobre los mosaicos de la parroquia de María Inmaculada en Modugno, realizados por el Centro Aletti. Véase: https://www.centroaletti.com/opere/chiesa-maria-immacolata-modugno-ba-2007/ [consultado: 08-06-2019] 
El análisis comparativo de las representaciones de la capilla Redemptoris $M a$ ter y de la parroquia de María Inmaculada en Modugno permite subrayar algunos aspectos relativos a la evolución producida en las obras del Centro Aletti. Así, en relación con el uso de los colores, en las primeras obras se percibe un contraste más violento entre las tonalidades. De esta explosión de colores se ha pasado, progresivamente, a «una luminosidad cada vez mayor entretejida con los colores de la tierra ${ }^{69}$. Los colores mantienen su fuerza, pero hay una búsqueda de una mayor armonía ${ }^{70}$.

Por otro lado, la comparativa de ambas representaciones revela también una transformación en la colocación de las teselas. Al principio, se presentaban de una manera más tosca, se potenciaban al máximo sus cualidades plásticas, su rugosidad, lo que conducía a una mayor confusión. Además, en los mosaicos iniciales, se subrayaban los desniveles de las teselas, lo que contribuía a esa sensación de desorden e irregularidad. Poco a poco estos desniveles se han ido disminuyendo y, en la actualidad, una de las normas que se siguen en el taller de arte del Centro Aletti es, precisamente, situar las teselas al mismo nivel. Esta transformación no ha de concebirse tan solo como un elemento puramente formal, pues tras esta regla subyace un fin más profundo: evitar que el ojo se fije especialmente en un determinado lugar y hacer que, en cambio, visualice todo el conjunto.

\section{EPISODIOS NEOTESTAMENTARIOS. MiLAGROS}

Como hemos señalado, es a comienzos del siglo IV cuando el carácter narrativo-descriptivo se impondrá con mayor fuerza al simbólico en las representaciones, y también es en estos momentos cuando diversos acontecimientos de la vida pública de Cristo, en especial, sus milagros, cobrarán un mayor protagonismo ${ }^{71}$. Con la plasmación de los milagros, una vez más, los artífices de estas imágenes querían subrayar la historia de la salvación, pues la curación física remitía a la curación espiritual del hombre.

De entre todos los milagros que realizó Cristo, en el arte paleocristiano destacarán especialmente las representaciones del ciego de nacimiento, del paralítico, de la hemorroísa o de la resurrección de Lázaro -de hecho, según Dulaey,

69 Nataša GOVEKAR, El rojo de la Plaza de Oro... [ver n. 7], p. 192.

70 Massimo CAMISASCA, Marko Ivan RUPNIK, Jonah LYNCH, La trasfigurazione della materia, Génova, Milano, 2011, pp. 29-33.

71 Juan PlazaOLa, El aniconismo... [ver n. 7], p. 24. 
este último es la representación del Nuevo Testamento más común en el arte funerario- ${ }^{72}$. Es por ello, por lo que en este estudio, vamos a centrarnos en esta figura.

El hecho de que estas escenas neotestamentarias adquirieran un mayor protagonismo y fueran representadas de forma más frecuente a partir del siglo IV, en concreto, tras la promulgación del Edicto de Milán, no significa que previamente no se hubiera realizado ninguna representación en este sentido. Autores como Bisconte han subrayado el ambiente tan ecléctico que existía ya en los siglos II y III, cuando se asienta el verdadero arte cristiano de las catacumbas romanas, donde encontramos tanto imágenes-signo como escenas bíblicas ${ }^{73}$. Así, en la catacumba dei Giordani, de San Calixto, de Domitila o de los Santos Pedro y Marcelino podemos contemplar imágenes del episodio de la resurrección de Lázaro que son anteriores al siglo IV.

\section{IV.1. La resurrección de Lázaro: Una promesa de eternidad}

Tenemos que tener en cuenta que los milagros de curación llevados a cabo por Cristo reflejan claramente su omnipresencia. Pueden ser leídos, por un lado, como la acción eficaz por parte de Jesús sobre el mal presente en el mundo y, por otro, como la prueba del poder de Dios en Cristo. Concretamente, la resurrección de Lázaro expresaría el poder de Cristo sobre la muerte y la anticipación de la propia resurrección, por lo que su representación en las catacumbas estaría íntimamente ligada al lugar donde se encuentran. Así lo destaca Zibawi al escribir que «la resurrección de Lázaro subrayaba la vida eterna de la que gozaba el creyente» ${ }^{74}$. Este hecho también se pretende enfatizar en las representaciones del Centro Aletti a través de la mirada de Lázaro: siempre mira a Cristo, pues ha experimentado con su propia vida que todo aquel que vea al Hijo, y crea en Él, tendrá vida eterna (Jn 6,40).

72 Martine Dulaey, L'Évangile de fean et l'iconographie: Lazare, la Samaritaine, et la pédagogie des Pères, en Cristian Badilita y Charles Kannengiesser (ed.), Les Pères de l'Église dans le monde d'aujourd'hui, Paris-Bucarest, 2006, p. 139. Véase también: Juan PlaZAOLA, Historia del arte cristiano... [ver n. 12], p. 12.

73 Fabrizio BisCONTI, La decoración de las catacumbas, en Vincenzo FiocCHI NiCOLAI, Fabrizio BisCONTI y Danilo MAZZOLENI (ed), Las catacumbas cristianas de Roma. Origen, desarrollo, aparato decorativo y documentación epigráfica, Regensburg, 1999, p. 123.

74 María Antonietta CRIPPA, Julien RIES y Mahmoud ZIBAWI (ed.), El arte paleocristiano... [ver n. 10], p. 96-97. 
Algunos autores, como Efrén de Siria (306-373), destacan la vinculación entre el episodio de Lázaro y la muerte y resurrección de Cristo (XVII, 7) ${ }^{75}$. Otros autores hicieron especial hincapié en el poder de la palabra divina sobre la muerte, como Cromacio de Aquileya (ca. 335-ca. 406) (Sermon 27: Sur la résurrection de Lazare, 4$)^{76}$. Este poder de la palabra podría estar reflejado en las imágenes paleocristianas a partir del modo en el que son retratadas las figuras: Cristo -siempre representado con un mayor tamaño- señala directamente a Lázaro. Por su parte, el Centro Aletti también quiere que en este episodio se refleje de forma clara que la llamada de Cristo es la llamada de la muerte a la vida y, por ello, se concibe este episodio como un clima de fiesta. De este modo, lo que debía ser un banquete fúnebre se ha transformado en una fiesta de la vida ${ }^{77}$.

De hecho, tanto en el mosaico del comedor del Centro Aletti en Roma (2002) (Fig. 3) como en el de San Giovanni Rotondo (2009) (Fig. 4), Lázaro resucitado y Cristo aparecen representados junto a Marta y María, que habían preparado, como señaló Juan en su evangelio, una cena «para festejar la vida de su hermano» (Jn 12,1-2) ${ }^{78}$. No obstante, el Centro Aletti señala todavía de forma más acentuada el carácter festivo de esta cena, pues se trata en realidad de una prefiguración del banquete celestial. Como señala Govekar, la fiesta de la comunión tiene solo una fuente: el don de la vida nueva en Cristo, de forma que quien la acoge porta ya el perfume de lo eterno en este mundo ${ }^{79}$.

Por otro lado, es interesante destacar que en la mayoría de las representaciones de la resurrección de Lázaro que realiza el Centro Aletti, este aparece con la cabeza descubierta, excepto en el mosaico de la capilla de las hermanas de Jesús Buen Pastor en Roma, donde su cabeza está parcialmente envuelta (Fig. 5). Rupnik parece así recordar las palabras del evangelista Juan, en las que señala que Lázaro tenía «atadas las manos y los pies con vendas, y el rostro envuelto en un sudario» (Jn 11,44). Este detalle del velo también fue tratado por los primeros cristianos en sus escritos. Así, como ha subrayado Dulaey, muchos de estos autores asociaron este elemento al velo de Moisés (Ex 34, 34), que es interpretado por san Pablo: «cuando se conviertan al Señor, el velo se quitará»

75 Éphrem, Commentaire de l'Évangile concordant ou Diatessaron, Paris, 1966, p. 307.

76 Chromace d'Aquilée, Sermons II, Paris, 1971, p. 113.

77 Nataša GoveKAR, La vita in Cristo... [ver n. 32], p. 50.

78 Comentarios sobre los mosaicos del comedor del Centro Aletti en Roma, realizados por el Centro Aletti. Véase: https://www.centroaletti.com/opere/refettorio-del-centro-aletti-roma-2002/ [consultado: 08-06-2019]

79 Nataša GoveKar, La vita in Cristo... [ver n. 32], p. 52. 
$(2 \text { Co } 3,16)^{80}$. Por tanto, el apóstol se refiere al momento del bautismo y también otros autores relacionarán la retirada del velo con este sacramento, como san Ambrosio de Milán, que escribe: «se quita de su rostro el velo que ensombrecía la verdad de la gracia que había recibido. Como ya ha sido perdonado, se le manda descubrir su faz, hacer patente su rostro» (II, 58) ${ }^{81}$.

La vinculación entre el pasaje de la resurrección de Lázaro y el bautismo es también concebida por el Centro Aletti. Así, en el mosaico de la cripta de la iglesia inferior de San Pío de Pietrelcina (Fig. 4), Lázaro aparece vestido de blanco, como explica Govekar, porque es la figura de todo bautizado que Cristo llama a salir de las tinieblas de la muerte para caminar en la luz de la vida ${ }^{82}$.

Por otro lado, es curioso señalar que, en algunas representaciones paleocristianas, el artífice quiso subrayar el movimiento que desprende la propia figura de Lázaro, como se observa de forma clara en la catacumba de San Calixto. Este detalle también se ha querido manifestar en las representaciones musivarias del Centro Aletti, en las que Lázaro se dispone a andar. De este modo, se persigue propiamente reflejar las palabras de Cristo: «iLázaro, sal de ahíl» (Jn 11, 43) (Fig. 5). $\mathrm{Y}$ de nuevo, este hecho, que aparece en las representaciones paleocristianas y que es recuperado por el Centro Aletti en la actualidad, tampoco pasó desapercibido por diversos autores antiguos. Así, Cromacio de Aquileya matizó: «quiso que Lázaro saliese atado de la tumba, en primer lugar, para manifestar claramente la fuerza de su poder divino, ya que Lázaro no solo fue alzado de la muerte, sino

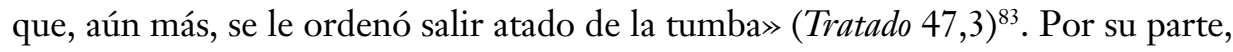
san Agustín comentará: «el Señor ciertamente le resucitó con su voz del sepulcro, clamando le devolvió el alma», por lo que «salió Lázaro ligado del monumento, no por sus propios pies, sino en virtud de quien le mandó salir fuera» (Plegaria de un afligido 101, II, 3$)^{84}$. Todas estas reflexiones subrayan, además, la conexión que ya al inicio de este estudio hemos señalado: el hecho de que los primeros autores conciban el pasaje de la resurrección de Lázaro como otro episodio de la historia de la salvación, al reflejarse el poder de Cristo sobre la muerte. Este mensaje también será manifestado en los mosaicos del Centro Aletti, como en el de la capilla de las hermanas de Jesús Buen Pastor en Roma: junto a la figura de Lázaro resucitado nos encontramos con una representación de Cristo crucificado. Como explica el

\footnotetext{
80 Martine DulaEY, L'Évangile de fean... [ver n. 72], p. 142.

81 Ambrosio, La penitencia, Madrid, 1993, p. 116.

82 Nataša GOVEKAR, La vita in Cristo... [ver n. 32], p. 50.

83 Cromacio de Aquileya, Comentario al evangelio de Mateo, Madrid, 2002, pp. 308-309.

84 Agustín, Obras de san Agustín. XXI. Enarraciones sobre los salmos, Madrid, 1966, p. 655.
} 
Centro Aletti, Lázaro sale de la tumba porque Cristo entra y acoge la muerte para que los hombres podamos vivir, para que la muerte no domine sobre el hombre ${ }^{85}$.

Finalmente, del mismo modo que se ha apuntado en las representaciones de Noé realizadas por el Centro Aletti, el estudio comparativo de las diversas representaciones de Lázaro permite subrayar una notable evolución. Además de percibirse en las representaciones más recientes un mayor uso de colores terrosos, de armonía cromática y de orden en la colocación de las teselas, Rupnik subraya cada vez más el uso de la línea como generadora de armonía, en especial, en sus fondos. Al principio, como se observa en el comedor del Centro Aletti en Roma (2002) (Fig. 3), las líneas son más irregulares. Poco a poco, en cambio, se percibe de forma nítida su trayectoria y movimiento completo, de manera que dicha armonía se aprecia con mayor claridad (Fig. 5). Además, este equilibrio se potencia con la creciente relación entre las líneas y las propias figuras. En los mosaicos iniciales, no parecía existir ninguna correspondencia entre ambas. Sin embargo, en la actualidad, se aprecia una mayor unidad entre lo abstracto y lo figurativo, una mayor cohesión de todo el conjunto. Las líneas fluyen, no obstruyen. Emergen como un estímulo, aportan equilibrio, acompañan al fiel a descubrir la imagen principal y, en ocasiones, también se utilizan para dividir las distintas escenas.

La evolución de los mosaicos del Centro Aletti, a partir de su estudio comparativo, también se percibe en el tratamiento de sus figuras, en especial, de sus rostros. De hecho, el elemento que más diferencia las figuras de los mosaicos iniciales y las que realiza el Centro Aletti en la actualidad está relacionado con la transfiguración de la carne. Al principio, los rostros eran muy rugosos (Fig. 3) y se observaban en ellos sombras muy marcadas. Poco a poco en los rostros de los mosaicos del Centro Aletti se subraya su transfiguración. Ello es debido a la utilización de un material concreto para la configuración de la carne de las figuras: el mármol amarillo de Siena, cuyas propiedades llevan a que apenas sean perceptibles sus cortes (Figs. 4 y 5 ).

\section{CONCLUSIONES}

Rupnik ve la necesidad de que el mensaje transmitido por una obra de arte sea inteligible al receptor, de forma que esta se manifieste como una obra dialogal. Para lograr una mayor comunicación de sus programas litúrgicos musivos tiene presente

85 Comentarios sobre los mosaicos de la capilla de las Hermanas de Jesús Buen Pastor, realizados por el Centro Aletti. Véase: https://www.centroaletti.com/opere/cappella-delle-suore-gesubuon-pastore-roma-2011/ [consultado: 08-06-2019] 
las obras creadas en las grandes épocas del arte oriental y occidental, entre ellas, las creaciones paleocristianas, que emergen como espacio de encuentro.

Así, en los mosaicos del Centro Aletti se observa una reinterpretación de las representaciones pertenecientes al arte paleocristiano, cuyo contenido subraya la historia de la salvación en la continuidad del Antiguo y Nuevo Testamento. Asimismo, Rupnik recupera la unidad entre la propia imagen y el texto que sirve de inspiración. Se preocupa por la creación de programas unitarios, por lo que muestra la correlación de escenas del Antiguo y Nuevo Testamento, situadas en un mismo espacio, característica propia del arte paleocristiano.

Todo ello se refleja en las figuras de Noé y de Lázaro, dos figuras que encontramos en el arte paleocristiano y que han sido recuperadas por el Centro Aletti. $\mathrm{El}$ estudio de sus representaciones paleocristianas refleja la interrelación entre las fuentes escritas y las artísticas, por lo que para la comprensión de su sentido profundo es necesario recurrir a los textos de las Sagradas Escrituras, fuentes litúrgicas, sermones o tratados teológicos. De igual forma, el análisis de las representaciones musivas del Centro Aletti nos lleva a la lectura de escritos de Padres de la Iglesia y de otros autores pertenecientes al cristianismo primitivo. Solo de esta forma, podremos llegar al sentido último de estas creaciones, que emergen como un ejemplo de arte litúrgico desarrollado en la actualidad. 
ANEXO
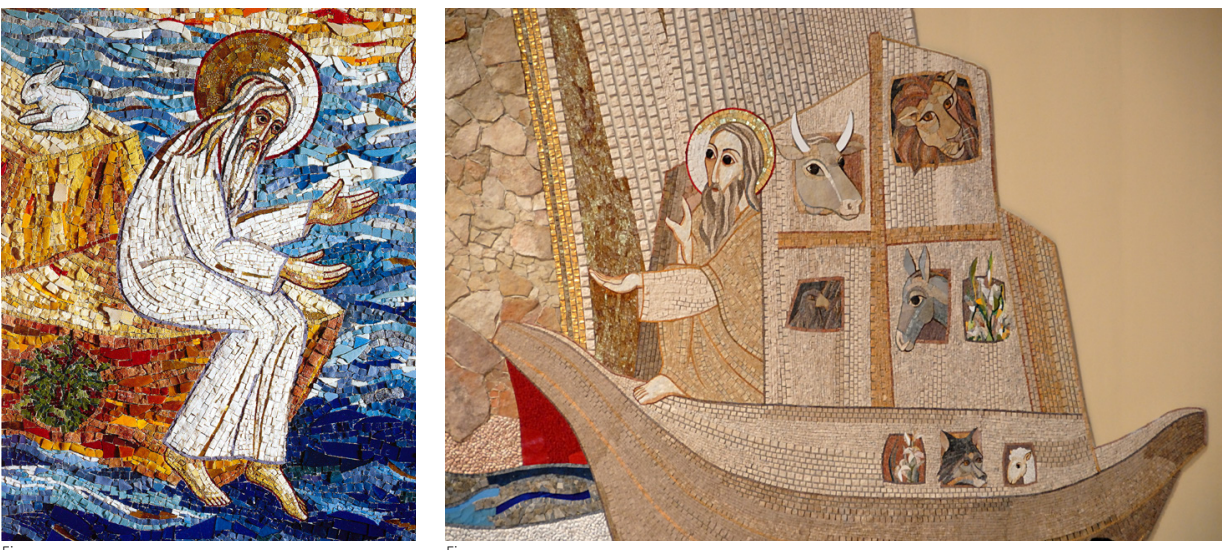

Fig. 1.

Fig. 2.
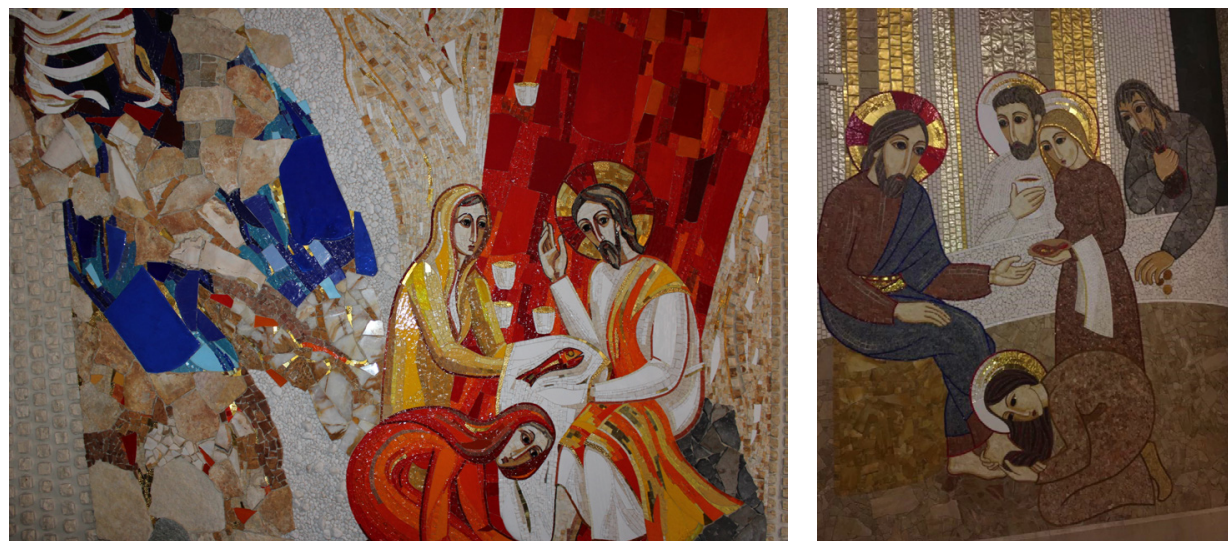

ig. 3

Fig. 4 .

Figura 1. Capilla Redemptoris Mater, Ciudad del Vaticano. 1996-1999. Fuente: Centro Aletti.

Figura 2. Parroquia de María Inmaculada, Modugno. Mayo 2007. Fuente: Centro Aletti.

Figura 3. Comedor del Centro Aletti, Roma. Octubre 2002. Fuente propia.

Figura 4. Cripta de la iglesia inferior de San Pío de Pietrelcina, San Giovanni Rotondo. Junio 2009. Fuente propia.

Figura 5. Capilla de las Hermanas de Jesús Buen Pastor, Roma. Noviembre 2011. Fuente propia.

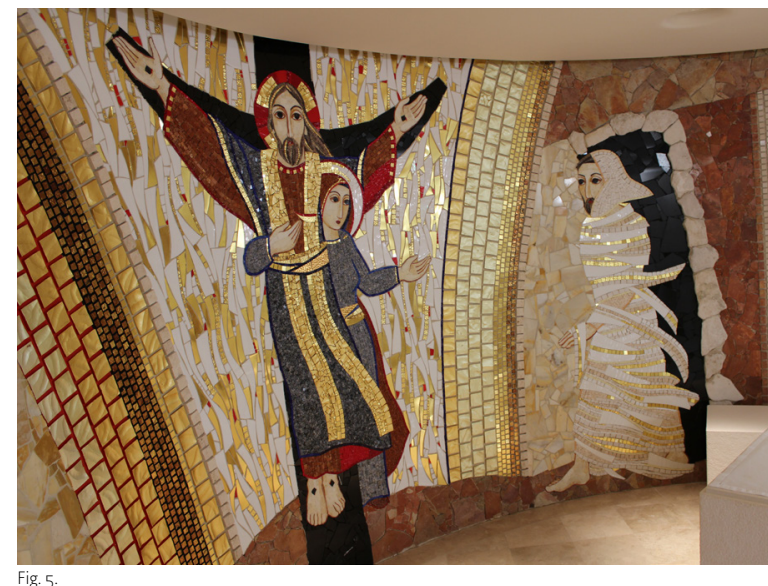




\section{REFERENCIAS BIBLIOGRÁFICAS}

\section{Fuentes}

AGUSTÍN, Obras de san Agustín. XXI. Enarraciones sobre los salmos, Madrid, 1966.

AGUSTÍN, Obras completas. XXXII. Escritos antidonatistas, Madrid, 1988.

AGUSTÍN, Obras completas de san Agustín, XXXI, Escritos antimaniqueos (2 Contra Fausto), ed. por Pío de Luis, Madrid, 1993.

AGUSTÍN, Obras completas de san Agustín. XVII. La Ciudad de Dios, ed. por Santos SANTAMARTA DEL Río y Miguel FuerTes LANERo, Madrid, 2001.

AMBROSIO, Explicación del símbolo, Los sacramentos. Los misterios, ed. por Pablo CERVERA BARRANCO, Madrid, 2005.

AMBROSIO, La penitencia, Madrid, 1993.

BASILIO DE CESAREA, Operum D. Basilii Magni caesariae Cappadociae quondam archiepiscopi prior tomus, Parisiis, 1547, f $128 \mathrm{r}$.

BASILIO DE CESAREA, El Espíritu Santo, ed. por Argimiro VELASCO DELGADO (Biblioteca de patrística, 32), Madrid, 1996.

CHROMACE D'AQUILÉE, Sermons II, Paris, 1971.

CROMACIO DE AQUILEYA, Comentario al evangelio de Mateo, Madrid, 2002.

CIRILO DE JERUSALÉn, Catequesis, ed. por Jesús SANCHO Bielsa, Madrid, 2006.

ÉPHREM, Commentaire de l'Évangile concordant ou Diatessaron, Paris, 1966.

FIRMICO MATERNO, L'errore delle religioni pagane, ed. por Ennio SANZI, Roma, 2006.

GREGORIO DE ELVIRA, Obras completas, Madrid, 1989.

HILARIO, Tratado de los misterios, ed. por Juan José AYÁN CALVO (Biblioteca patrística, 20), Madrid, 1993.

IRENEO, Contra las herejías. Libro IV, ed. por Jesús GARITAONANDIA, Sevilla, 1994.

ISIDORVS, Expositio in Vetus Testamentum Genesis, Freiburg, 2009.

JEAN CHRYSOSTOME, Sermons sur la Genèse, ed. por Laurence BROTTIER, Paris, 1998.

JUAN DAMASCENO, Homilias cristológicas y marianas, ed. por Guillermo PONS, Madrid, 1996.

JUSTino, Lo mejor de fustino mártir, Apología I, Apología II. Diálogo con Trifón, ed. por Alfonso ROPERO, Barcelona, 2004.

MAXIMUS, The sermons of St. Maximus of Turin, Newman Press, New York, 1989.

MELITÓn, Sur la Pâque et fragments, ed. por Othmar PERLER, Paris, 1966.

MÉTHODE, Du livre Arbitre, ed. por A. VAILlanT (Patrologia Orientalis, 22), Turnhour, 2004.

ORIGEN, Homilies 1-14 on Ezekiel, ed. por Thomas P. SCHECK, New York, 2010.

ORÍGENES, Sobre los principios, ed. por Samuel FERNÁNDEZ (fts. patrísticas, 27), Madrid, 2015.

SS. Patrum, Aegyptiorum. Opera omnia. Praecedunt Philonis Carpasii, Asterii Amaseni, Nemesii Emeseni, Hieronymi Graeci, Turnholti, 1967.

TERTUliANO, El bautismo. La oración, Madrid, 2006. 


\section{Bibliografía}

APA, Mariano, ClÉMEnt, Olivier y VALEnZiano, Crispino (ed.), La Capilla Redemptoris Mater del Papa fuan Pablo II, Burgos, 2002.

BECKWITH, John, Arte paleocristiano y bizantino, Madrid, 1997.

BERnARDI, Piergiuseppe, I colori di Dio. L'immagine cristiana fra Oriente e Occidente, Genova, 2007.

BISCONTI, Fabrizio, La decoración de las catacumbas, en Vincenzo FIOCCHI NiCOLAI, Fabrizio BIsCONTI y Danilo MAZZOLENI (ed), Las catacumbas cristianas de Roma. Origen, desarrollo, aparato decorativo y documentación epigráfica, Regensburg, 1999, pp. 71-144.

BisCONTI, Fabrizio, Temi di iconografia paleocristiana, Città del Vaticano, 2000.

CAMISASCA, Massimo, RUPNIK, Marko Ivan, LYNCH, Jonah, La trasfigurazione della materia, Génova, Milano, 2011.

Campatelli, Maria, Leggere la Bibbia con i Padri. Per una lettura credente delle Scritture, Roma, 2009.

CRIPPA, María Antonietta, RIES, Julien y ZibaWI, Mahmoud (ed.), El arte paleocristiano. Visión y espacio de los orígenes a Bizancio, Madrid, 1998.

DANIÉLOU, Jean, Sacramentos y culto según los santos Padres, Madrid, 1964.

DANIÉlOU, Jean, Símbolos cristianos primitivos, Bilbao, 1993.

DUlAEY, Martine, Bosques de símbolos. La iniciación cristiana y la Biblia (siglos I-IV), Madrid, 2003.

DULAEY, Martine, L'Évangile de fean et l'iconographie: Lazare, la Samaritaine, et la pédagogie des Pères, en Cristian BadiLita y Charles Kannengiesser (ed.), Les Pères de l'Église dans le monde d'aujourd'bui, Paris-Bucarest, 2006, pp. 137-164.

GARCía MAHÍQUES, Rafael, La adoración de los Magos. Imagen de la epifanía en el arte de la antigiiedad, Vitoria, 1992.

GARCía MAHÍQUES, Rafael, Iconografía e iconología. 1. La historia del arte como historia cultural, Madrid, 2008.

GaTTI, Vincenzo, L'arte nella chiesa, en Arte Cristiana 748 (1992), pp. 49-56.

GOVEKAR, Nataša, El rojo de la Plaza de Oro. Entrevista de Nataša Govekar con Marko Ivan Rupnik sobre arte, fe y evangelización, Burgos, 2013.

GOVEKAR, Nataša, La vita in Cristo con i mosaici della cripta di San Pio, Roma, 2014.

GOMBRICH, Ernst H., Los usos de las imágenes. Estudios sobre la función social del arte y la comunicación visual, Barcelona, 2003.

GRABAR, André, El primer arte cristiano (200-395), Madrid, 1967.

GRABAR, André, Las vías de la creación en la iconografía cristiana, Madrid, 1993.

GUARDINI, Romano, Imagen de culto e imagen de devoción. La esencia de la obra de arte, Madrid, 1960.

MaZZA, Enrico, Tipologia come metodo di lettura biblica e di fondamento dell'immagine, en Arte Cristiana, 737-738 (1990), pp. 107-110.

PlazaOla, Juan, Historia del arte cristiano, Madrid, 1999. 
RATZINGER, Joseph, J., El espíritu de la liturgia, Una introducción, Madrid, 2007.

RÉAU, Louis, Iconografía del arte cristiano. Introducción general, Barcelona, 2000.

RoDrígueZ VELASCO, María, Iconografía, imagen y estética en los mosaicos de Marko Ivan Rupnik: una mirada desde la tradición, en Debate Actual 13 (2009), pp. 8-37.

RodrígueZ Velasco, María (ed.), Tradición y Modernidad en la obra de Marko Iván Rupnik, Madrid, 2013.

RUIZ de LOIZAGa MARTíN, María, Hacia un arte litúrgico, según la concepción de Marko Ivan Rupnik. Reflexiones sobre el arte sacro, en Scripta Theologica. 49 (2017), pp. 619643.

RuIZ DE LOIZAga MARTíN, María, La semplificazione delle forme. Influenza di Matisse nei mosaici di Marko Ivan Rupnik e il Centro Ezio Aletti, en Collectanea Franciscana, 87 (2017), pp. 613-634.

RUPNIK, Marko Ivan, Applicazione del Concilio: quale arte per la liturgia?, en Notitiae, 471472 (2005), pp. 579-587.

RUPNIK, Marko Ivan, Una belleza para el encuentro, Madrid, 2013.

SEBAStián, Santiago, Iconografía Medieval, Donostia, 1988.

SEbastián, Santiago, Mensaje simbólico del arte medieval. Arquitectura, Liturgia e Iconografía, Madrid, 2009.

ŠPIDLÍK, Tomáš y RUPNIK, Marko Ivan, Narrativa dell'immagine, Roma, 1996.

ŠPIDLÍK, Tomáš y RUPNIK, Marko Ivan, La fe según los iconos, Burgos, 2003.

Velasco Quintana, Pablo y RodrígueZ Velasco, María, Marko Ivan Rupnik. Una nueva forma de creación frente al subjetivismo contemporáneo, en Debate Actual, 13 (2009), pp. 118-127.

VERDOn, Timothy, Giovanni Paolo II e le arte visive, en Arte Cristiana, 828 (2005), pp. 165 170.

VERdon, Timothy (ed.), L'arte cristiana in Italia. Origini e Medioevo, Milano, 2005. 